\title{
Reviewers in this issue
}

\section{Dr. U. K. Taufiqun Nessa}

Professor of Community Medicine

Delta Medical College, Dhaka, Bangladesh

\section{Dr. S. M. Fazlul Karim}

Professor of Biochemistry

Delta Medical College, Dhaka, Bangladesh

\section{Dr. Nadira Islam}

Professor of Physiology

Delta Medical College, Dhaka, Bangladesh

\section{Dr. Md. Rafiqul Islam}

Professor of Paediatrics

Delta Medical College, Dhaka, Bangladesh

\section{Dr. Ayesha Hassan}

Associate Professor of Dermatology

Delta Medical College, Dhaka, Bangladesh

\section{Dr. Rezaul Farid Khan}

Associate Professor of Community Medicine

Delta Medical College, Dhaka, Bangladesh 
To equip you with an effective weapon against aerobic gram-negative bacteria

\section{Atreon \\ Aztreonam \\ $500 \mathrm{mg} \mathrm{IM} / \mathrm{IV}$ injection \\ $1 \mathrm{gm}$ IM/IV injection \\ 2 gm IV injection}

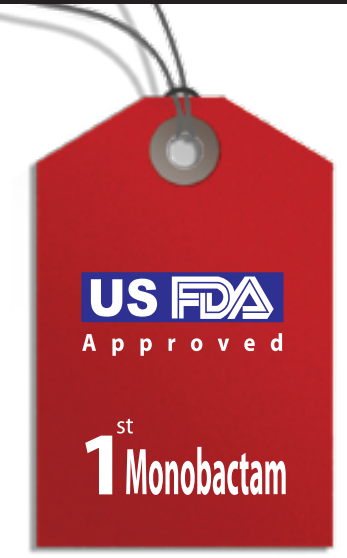

The drug of choice in life-threatening aerobic gram-negative infections

To treat poly-microbial infections effectively

$$
\begin{gathered}
\text { The super-active antibiotic } \\
\text { against poly-microbial bio-film }
\end{gathered}
$$

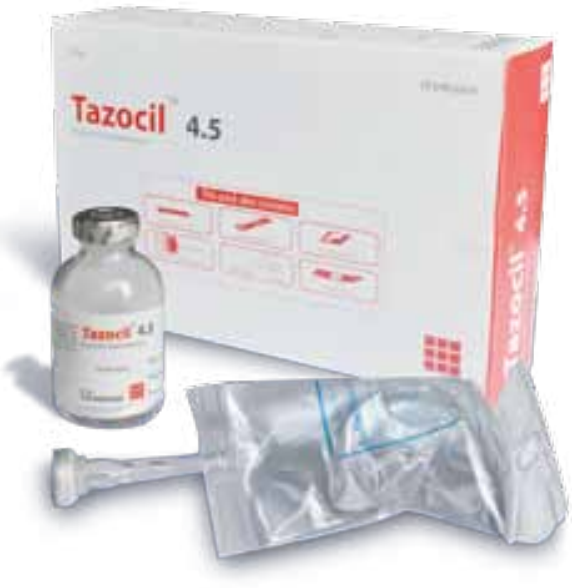

Approved for paediatric use (age 2 months and above) 


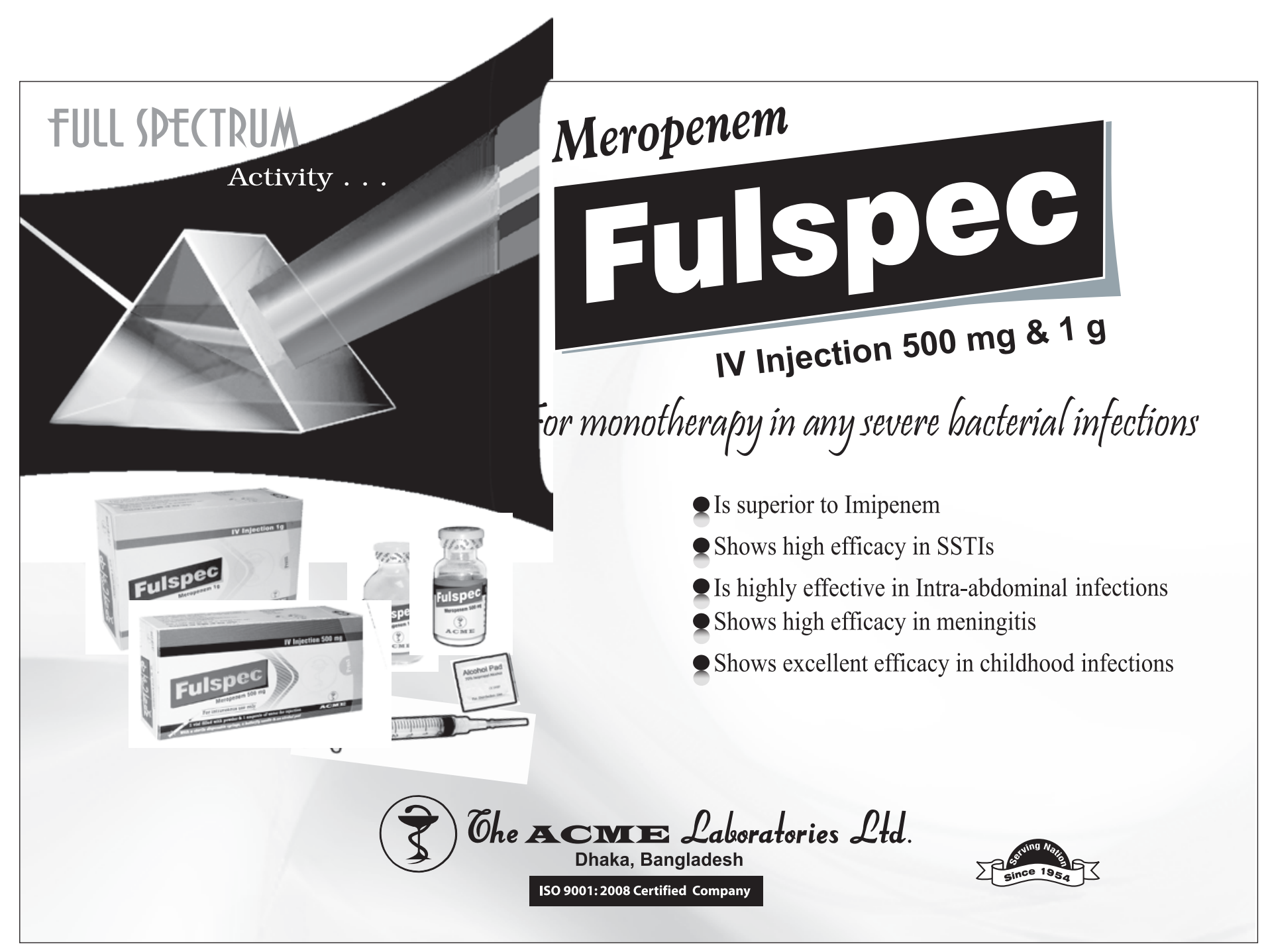

